\title{
The Application Study of Electronic Farming in the Ecology Construction in Chinese Tropical Area
}

\author{
Meng Meng, Xiaofei Zheng*, and Jiabin Wang \\ Institute of Scientific and Technical Information, CATAS, 571737, Danzhou Hainan, China \\ \{Mengmengsir,zs-xf,jia_bin_na\} @163.com
}

\begin{abstract}
In this paper, which takes Hainan as an example, analyze the application of Electronic agriculture affairs in the process of building ecology, and aims at proposing the application strategy of Electronic agriculture affairs. The paper points out the advantages of applying electronic agriculture affairs in building ecology and the ways to carry it out. It takes the application of electronic agriculture affairs of Hainan as the focal point and analyzes its application mode. Together with the analysis of the application situation in other areas, it summarizes the problems in the process of applying electronic agriculture affairs. At last, it proposes the countermeasures and solutions in application of electronic agriculture affairs.
\end{abstract}

Keywords: Ecology Construction, Electronic Farming, Agricultural Informatization, Chinese Tropical Area.

\section{Introduction}

Information technology has greatly changed the mode of agricultural development and reform, in particular, had a huge impact on the interaction between the markets for agricultural products and agricultural production.

The core to build a new socialist ecology is to develop the agricultural economy and increase rural incomes. It is undoubtedly an effective way to reform the traditional management of agriculture for building new ecology. Electronic agriculture affairs, as an advanced commercial pattern, has great advantages in improving the industrialization degree of agriculture, adjusting agriculture structure, reducing the transaction cost, and expanding the market of the sale of agricultural products.

As the country's largest special economic zone and international tourism island, Hainan is an agricultural province; agricultural information degree of market determines the level of results and to play the role of bridgehead of the new socialist ecology construction in Hainan. Although the province's agricultural information market in recent years has made great progress, especially one-year term of Hainan Winter Fair, rural economic development of Hainan and the surrounding provinces and cities of the more advanced market demand, technology and industrial development

\footnotetext{
* Corresponding author.

D. Li and Y. Chen (Eds.): CCTA 2013, Part I, IFIP AICT 419, pp. 1-9, 2014.

(C) IFIP International Federation for Information Processing 2014
} 
agricultural information. Hainan agricultural market development status, the market is not mature, the trading behavior is not standardized, even the existence of low-quality information, false information events.

The Hainan is a major agricultural province; therefore, to the establishment of a sound, comprehensive agricultural information system to promote rural economic development of Hainan is the urgent task of the agricultural province.

\section{New Socialist Ecology Farm Applications Countermeasures}

To become boosters of the socialist new socialist ecology construction, the implementation of e-agriculture is very complex system engineering. E-agriculture in the new socialist ecology construction applications may encounter a variety of problems, for the problems that may arise, as well as the construction of a new socialist ecology in the case of successful application of e-agriculture, domestic socialist ecology building applications for electronic farm to make some suggestions.

\subsection{The Establishment of Agricultural Information Service System}

The establishment of agricultural information service system and gradually establish agricultural means of production and supply system; processing of agricultural products, sales system; agricultural research, teaching, technology extension system; crop seeds, poultry livestock cultivation, breeding, processing, marketing system and agricultural quality inspection and supervision system, a series of agricultural information service system.

\subsection{Government Supports}

To guide the development of the advanced countries of agricultural products e-commerce demonstration system experience shows that without government involvement and support in e-commerce of agricultural products is difficult to smooth progress. The construction of e-agriculture as the main government departments, and deregulation operating services, promote the diversification of service model, and the promotion of e-agriculture targeted. Government to the grassroots agricultural sites, below the county grass-roots promotion of agricultural technology organizations, rural information service enterprises, farmers, professional and technical associations and intermediary organizations to provide support in all aspects, so that they can on the joint network, the second line people. To strengthen the Government's efforts to support the provision of public information products and services to the majority of farmers, the provision of fiscal and monetary policy support, standardize the order of the information services market. 


\subsection{Train a New Generation of "Electrical Farmers"}

To take various measures to train a new generation of "electrical farmers" the quality of farmers is the key to China's agricultural modernization, but also an important factor in the development of e-commerce of agricultural products. The long-term goal of the departure from the modernization of agriculture, to develop detailed planning to take concrete measures to step-by-step phases, get down to improve farmers' cultural knowledge and agricultural technology.

\subsection{Establish the Appropriate Supply Chain and Logistics Systems}

To establish the appropriate supply chain and logistics systems agriculture has obvious regional and seasonal characteristics of the different regions, different seasons of the agricultural products to be linked between agriculture and e-commerce platform, which requires the establishment of effective supply chain system, as well as agricultural database. Establish the agricultural supply chain of agricultural logistics system.

\subsection{Determine the E-farm Demonstration Sites to Comprehensively Promote Information Technology in Rural Areas Provide a Demonstration Effect}

The limited local finance, promote e-agriculture construction impossible to carry out large-scale. Therefore, local governments in promoting informatization construction, make sure that the construction of demonstration sites, building on a small scale. Leading enterprises, agricultural cooperative organizations, large breeding, as the focus of information construction. In the demonstration sites should be taken to the idea of rapid application of high standards of quality, low-input, and to adopt a unified program, unified standards, unified integrated, hierarchical implementation approach, the accumulation of experience in the construction. This information construction in rural areas is very important, and helps to reduce the blind investment and resource conservation, and can find the information on the real needs of rural residents.

\subsection{Market-Oriented Operation Mechanism for E-agriculture Construction Refueling}

E-agriculture has a strong public interest, and to highlight the social benefits is a long-term task, you must combine government promotion, guidance and market mechanisms. In addition to government departments, various social or business organizations can become direct information service principal, the Government can play an organization to promote and oversee the manager's role, and insisted that the government-led emphasis on the basic role of the market, accelerating the development of the information technology market players, play to their enthusiasm; the role of government to gradually Go to actively create a favorable policy environment for up to encourage and support all kinds of social forces to carry out the socialization of information services for the majority of farmers, to promote e-agriculture. 
As long as the governmental organizations, to co-ordinate the planning, funds, technical support. Development of low-cost, high-tech, systems-oriented integrated innovation; e-agriculture will be able to achieve brilliant results. Which is conducive to narrow the urban-rural digital divide, break the urban-rural dual structure; conducive to the promotion of farmers to change their ideas and improve quality; conducive to modern technology and the combination of agriculture, strengthen the comprehensive agricultural production capacity-building, the construction of these e-agriculture, promote rural economic and social development played an important role of government is a way of building a new socialist ecology.

\section{A New Socialist Ecology E-farm Application of Innovative Solutions}

\subsection{Overall Program Architecture}

After a large number of requirements analysis, in-depth study on the construction of agricultural information, a comprehensive plan to provide a set of agricultural information technology solutions, mainly from three aspects:

First offers a range of hardware and software products for the agricultural production information to meet the agricultural prenatal, delivery, postpartum and other aspects of the high-tech needs, enhance scientific and technological content of agricultural production, and enhance the market competitiveness of agricultural products.

Followed by agriculture-related enterprises to provide information technology solutions, from simple to complex embodiment, a comprehensive plan for the gradual implementation of agriculture-related enterprises gradually increase the level of information, meet agricultural production, operation in science and technology, market, management, personnel and other information needs.

Again to provide information services for the government, enterprises, scientific research institutions, farmers, build modern rural information service system. Vast amounts of technology and market data sources as the basis of all the modern means of communication, build a convenient, fast, intelligent, high-speed two-way information channel and trading platform to meet all aspects of the information needs of all levels.

\subsection{Agricultural Production Information-Precision Agriculture System Solutions}

Precision agriculture by 10 system, namely, global positioning systems, field information collection system, agricultural remote sensing monitoring system, irrigation and geographic information systems, agricultural expert systems, intelligent farm machinery systems, environmental monitoring systems, system integration, network management systems and training system, its core is a perfect farmland geographic information system (GIS), can be said that the full integration of a new type of agricultural information technology and agricultural production. Precision agriculture is not too much emphasis on high-yield, and the main emphasis on 
effectiveness. It agriculture into the digital information age is an important direction of development of agriculture in the 21 st century.

Precision agriculture is based on information technology support, based on the spatial variability, positioning, timing, quantitative implementation of a set of modern farming operations technology and management system, a new type of agriculture is fully integrated information technology and agricultural production. Precision agriculture technology system, including the different levels of the system, based on the application software.

System Software: Average common Windows operating system software;

Basic software: Can be used for secondary development of GIS software such as MapInfo, Arc / Info; application programming software, such as VB, VC, the underlying database software;

Applications: Spatial information management and analysis software; farmland GIS precision agriculture as the foundation of the database; software and data exchange software, software and hardware interface software; GPS and GIS interface software, GPS, GIS and intelligent agricultural interface software, field information collection and GIS interface software; analysis and decision software and agricultural expert systems, crop growth and numerical simulation, farm management decision-making software.

\subsection{Agricultural Production Management Program}

Analog agricultural experts ponder the reasoning process to solve the farmers' problems in the production process a set of utility software. Can also be run separately to run on a computer to solve due to the usual fertilization irrigation, pest and disease control, information understanding timely grasp inaccurate not the right response to the losses caused by integration with the local agricultural site. Agricultural expert system to guide scientific farming, science and sprinkle the medicine, scientific fertilization, scientific pest control, reduce the dangers of instability and improve the economic efficiency of the agricultural industry. Agricultural expert system has a unique intelligent reasoning, the use of multimedia information technology, graphic audio and Mao popularization of agricultural production technology guidance of scientific farming.

The main features of the system:

Fool: The color of the man-machine interface, style design with the current mainstream WINDOWS XP interface style; method of operation, the choice of the list (such as a drop-down list, combined list), greatly reducing the user manual input operation; the form of a Windows Explorer on the system to use interface enables users to easily get started operation; tree structure in the form of knowledge representation, knowledge system a clear at a glance.

Intelligent: The system according to the relevant parameters of the user-selected pest and disease onset of symptoms, body characteristics, automatic judgment, analysis, results given by the inference engine, such as the name of the pest and disease control methods. 
Interactivity: Agriculture and animal husbandry expert professional interaction through the system with the user, with a professional online conversation function module, the user of the problem and reply to the experts in this line docking.

Simple: The system comes with a data management system that provides a simple maintenance platform, according to the instructions to fill in the data, the system can automatically and immediately to knowledge extraction and interpretation, the required knowledge stored in the underlying database maintenance The process is very simple.

\subsection{Pest Control Forecasting System}

Solve local plant protection departments pest forecast forecasts of information technology, it is a combination of software technology, network technology and plant protection technology intelligence software, specifically designed for plant protection forecasting, for all aspects of the plant protection work process design, effectively reduce the workload of the plant protection of forecasting, improve work efficiency.

This system is fully functional, related to all aspects of plant protection, the system consists of ten subsystems, namely: pest data upload and release system, the pest database management system, integrated pest and disease information inquiry system, reporting and management systems, pest and disease forecasting Statistical Analysis System, pest and disease forecast data mining system, pest prediction visual modeling system, pest multimedia data management systems, pest and disease forecasting model simulation system and disaster fuzzy evaluation system. The function of each system is described as follows:

(1) Under the network environment pest data upload and release system

The system through the Internet site of data to collect, collates, publishes, uploads and issued. Around the state, counties and cities statistics and other materials to document form on the aggregated upload. The provincial stations under the local cities and counties can also be down directly send text notifications.

(2) Pest and disease information query system

The data management module embedded in a strong data query functions. Query objects include: data table fields, data sheet describes the information, data sheet classification, data tables, fields, field descriptions. You can query data tables, fields, and records. Comparison include: equal, not equal, fuzzy comparison, equal to the null value is not equal to a null value.

(3) Reporting and management system

Report Manager free report table-like design to achieve a good header of the freedom to customize, easy to use and powerful. Users according to the actual need to design a report header, select the matching data sheet and select the corresponding field for each column, then a simple parameter settings to the preview of the report, print.

(4) Pest forecasting Statistical Analysis System

The statistical analysis of regression prediction method is the prediction of agricultural pests and diseases has important practical significance. System and multiple linear regression modeling and prediction function, intuitive modeling guide makes the model easy to use, standardized and rigorous. Save the establishment of a 
good model, forecasts, select the data table corresponding to the model library model input argument value, you can calculate the predicted value and the predictive value of interval estimation.

\subsection{Agricultural Enterprise Information Solutions ----- Supply and Demand of Agricultural Products Information Intelligent Service System}

Based on fully research the current agricultural enterprises informatization construction features of the core of enterprise resource plan (ERP) agricultural enterprises informatization construction program, including the construction of network infrastructure, enterprise Internet (LAN and wide-area network), Enterprise Resource Management and e-commerce in order to achieve full sharing and utilization of information resources. Using Internet resources to establish an online order service platform, logistics and distribution system, to achieve the full range, removable, integrated centralized management and real-time process control; fully tap the business information resources, and provide an important basis for management decisions.

Agricultural supply and demand information intelligent service system integration with local rural network to forecast the trend of prices of agricultural products through intelligent analysis, analysis of market conditions, to automatically search market supply and demand information, analysis and retrieval, automatic matching of supply and demand of agricultural products. Agricultural supply and demand information intelligent service system is a data acquisition, data cleansing, data mining analysis, intelligent prediction, visualization, display and other subsystems organic whole, mining analysis and intelligent prediction from each other, complement each other to form a comprehensive smart trends predictive analysis methods, and ultimately the formation of an integrated system.

Agricultural supply and demand information intelligent service system main function is to: show the prices of major agricultural spatial distribution, the timing variation trends of the market price, supply and demand information intelligent docking; market-oriented agricultural structure adjustment for government departments; agriculture and animal husbandry enterprises, large, Association, and even ordinary farmers show the dynamic and intelligent analysis.

(1) The prices of agricultural data mining method

Based on the prices of agricultural data warehouse, variety, price, quality, production, origin, property, classification, clustering, association, timing and other mining analysis, reveal price trends influencing factors and reasons, such as: the impact of high prices, , low distribution area characteristics, population characteristics, the analysis of the seasonal characteristics of inter-city price fluctuation relationship between varieties prices ebb and flow, and the industrial structure, price and agro-meteorological relationship analysis.

(2) Commodity price trends analysis and forecasting methods

Price data and spatial distribution of the data according to the timing of agricultural products, the establishment of a data mart, through statistical analysis, support vector machines, neural network and wavelet chaotic prediction method for trend analysis, timing analysis and cycle analysis, forecast the trend of prices of agricultural products. 
(3) Agricultural supply and demand information intelligent docking method

The use of Ontology-based Web information mining, extraction, semantic analysis technology, combined with the price, quantity, quality, location and other attributes intelligent docking of supply and demand information for the user or request information, the priority of the request or for competitiveness automatic docking to the user. Information is available through the means of transmission, such as: voice systems, portals, SMS platform, customization and broadcast push.

\subsection{Rural Information Technology Solutions - The Rural Market Service System}

Existing agricultural market information collection channels and collection points, unified and standardized information collection system of various types of agricultural products, as well as market supply and demand and prices of agricultural commodities (including fertilizers, pesticides, plastic sheeting and other agricultural markets, food, vegetables, livestock, aquatic products and other agricultural products market information). In the data acquisition system based on the integration of existing information media, real-time information released by e-mail, pager, SMS, etc. In addition to real-time information on the Internet, information is automatically released. Processing, sorting and analysis of information resources, analysis and forecast the agricultural main varieties of domestic and international market conditions, production and marketing situation. Use the web to provide the means of communication in the online transaction an exchange of information between the two sides, trading contact stylized system; take online auction as the main mode of trading Contact by e-mail, mobile phone text messages and paging intelligent an exchange of information. Create an online agricultural trade information service platform, to achieve real-time online deliberation trading conditions.

\section{Conclusions}

In this paper, some of the problems of e-farm applications in the construction of new socialist ecology, some countermeasures, and launched on the basis of the application of innovative solutions for e-agriculture, including agricultural information technology, the agriculture enterprise information and rural information of the solution.

\section{References}

[1] Chen, X.: The evolution of agricultural informationization and countermeasures. Science and Technology Management Research (7), 437-03 (2009)

[2] Yong, C.: To speed up the agricultural informationization construction to promote agricultural modernization development. Journal of Inner Mongolia Science and Technology and Economy (9), 63-64, 18 (2009)

[3] Zhao, C.: Henan province rural informatization way and strategy analysis. Journal of Management Informationization in China 12(17), 81-83 (2009)

[4] Du, X., Zhu, Q., Wen, H.: New rural informationization present situation and development countermeasures. Rural Economy (8), 95-98 (2009) 
[5] Huan, S.H., Sheoran, S.K., Wang, G.: A review and analysis of supply chain operations reference (SCOR) model. Supply Chain Management 9(1), 23-29 (2004)

[6] Choi, T.Y., Dooley, K.J.: Supply networks and complex adaptive systems: control versus emergence. Journal of Operations Management 19(3), 351-366 (2001)

[7] Zhang, A.: What time thinking about the construction of speed up agricultural informationization. Journal of Agricultural Science and Technology (1), 17-18 (2007)

[8] Yang, X.: Thinking about China's rural informatization construction. World Agriculture (3), 19-21 (2008)

[9] Jiang, X.: Strategy analysis of agricultural informatization development. Journal of Agricultural Mechanization Research (3), 32-35 (2005)

[10] Liu, W., Ma, X.: Agricultural information technology development research in the construction of new socialist rural. Agricultural Science of Anhui (12), 2911-2912 (2006) 